\title{
Efficiency and Operation Studies on Renewable Energy Systems as Future Energy Resources
}

\author{
Vipul Pandey \\ M. Tech Scholar \\ Truba Institute of Engineering and \\ Information Technology \\ Bhopal, M.P. India \\ vipulskills@gmail.com
}

\author{
Dr. Rajeev Arya \\ Director \\ Truba Institute of Engineering and \\ Information Technology \\ Bhopal, M.P. India \\ rajeev.arya@trubainstitute.ac.in
}

\author{
Shravan Vishwakarma \\ Professor \\ Truba Institute of Engineering and \\ Information Technology \\ Bhopal, M.P. India \\ shravanmits@gmail.com
}

\begin{abstract}
The growth of the renewable energy sector in India has been substantial, including for the production of electricity from renewable sources. Renewable energy is energy produced from natural resources such as sunlight, wind, rain, tides and geothermal energy which are renewable (naturally replenished). Even with decentralized systems, the growth of solar lighting systems for private homes was $300 \%$, solar lanterns by $99 \%$ and solar photovoltaic water pumps by $196 \%$. This article presents renewable energies. In addition, solar energy, wind energy and biomass are described.
\end{abstract}

Keyword: Solar Energy, Wind Energy, Renewable Energy, Sunlight.

\section{INTRODUCTION}

Clean renewable energy has become an important part of the current energy structure and also an important direction for energy development. As typical representatives of renewable energy, wind and solar energy have been a large-scale development and wide application. Due to the limitation of energy transfer, "energy" has become the primary form of use. Renewable energies are sensitive to external environmental factors and show significant diffusion and volatility. A large power grid due to the safe operation of the power grid has significant negative effects. Many studies have suggested the use of microgrids as a unified integration of different types of energy and load to form independent and interconnected energy systems to reduce the independent operation of the power system to negative effects and improve the efficient use of energy by the system [1] - [2]. While the unique mode of energy use and the relatively independent mode of operation between power systems lead to the problem of insufficient energy consumption and low utilization rate in the system, this leads to excess renewable energy and not to enjoy full of the maximum overall benefits of energy. Therefore, this research focused on the characteristics of the interconnection of renewable energies and the interrelation of the collaboration for energy storage, analyzed the problems encountered in the collaboration process and proposed a model for improving energy efficiency [3]. Solar and wind energy is environmentally friendly and environmentally friendly. However, due to their intermittent and fluctuating properties, their use and effectiveness are severely limited. In order to improve the efficiency of the use of solar, wind and other new energy sources, wind and solar power generation systems, wind storage systems, systems The generation of light storage energy and storage systems wind energy are gradually gaining people's attention [4].

\section{LITERATURE REVIEW}

Lu, Y. et al. [5] This study provides an overview of sustainable energy policies that promote renewable energy by presenting the history of energy policy development in five countries, namely H. United States, Germany, United Kingdom, Denmark and China. An overview of articles promoting the development of a sustainable energy policy and their modeling is produced. It can be seen that the energy efficiency standard is one of the most popular energy saving strategies for buildings, which is dynamic and renewed according to currently available technologies. The feed-in tariff has been widely used to promote the use of renewable energies, which has been successfully demonstrated in several countries.

AtikaQazi et al. [6] This study highlights that a lack of public awareness is one of the main obstacles to the adoption of renewable energy technologies. The results of this study show that global energy crises can be overcome by integrating renewable energy sources into energy production. To facilitate the development of renewable energy technologies, this systematic review highlighted the importance of public opinion and performed real-time analysis of public tweets. This analysis of sample tweets is a relatively recent initiative in a comprehensive study aimed at 
drawing the attention of future researchers and policy makers to public opinion and recommending implications for academia and industry.

P. asantewaaowusu et al. [7] The study suggested policy measures and recommendations that, if considered, would help meet the renewable energy goal of reducing emissions, mitigating climate change and creating an environment and an environment clean energy for all future generations to provide.

Ed. KazimierasZavadskas et al. [8] the main objective of this article is to provide a systematic overview of MCDM techniques and approaches to problems related to sustainable and renewable energy systems. The results of this review confirm that MCDM techniques can help stakeholders and decision makers uncover some of the uncertainties associated with environmental decisions, and these techniques show a growing interest from previous scientists in applying these techniques to solve various steps sustainable and renewable energy systems.

Abbas Azarpour et al. [9] in this article, issue-related renewable energies (biomass sources, wind, solar, hydroelectric and geothermal energy combined) are discussed from a technical, environmental, health and economic point of view. Renewable energy supply from domestic wind, hydroelectric power plants, solar energy, geothermal energy, and biomass waste may clearly not meet the energy demand. The magnitude of the demand for these resources together would be extremely formidable, and there will certainly be problems in integrating large quantities of intermittent renewables into existing supply systems.

\section{RENEWABLE ENERGY}

All energy sources on earth come from the sun in the form of solar energy, which is completely sustainable and could be converted into other useful forms of energy. Many factors must be taken into consideration to achieve sustainable development of energy supply, as renewable energy resources are essential. Other factors are the effects on the environment, health and profitability. Over the past two decades, environmental degradation has become more evident, with most of the future problems related to current energy sources. The main areas of environmental impact can be classified as follows

-Major environmental accidents

-Water pollution

-Land use and siting impact

-Radiation and radioactivity
-Solid waste disposal

-Hazardous air pollutants

-Ambient air quality

-Acid rain

-Stratospheric ozone depletion, and

-Global climate change (greenhouse effect)

\section{A. Wind Energy}

Wind occurs when the equatorial regions of the Earth receive more solar energy than the polar regions, which creates large convection currents in the atmosphere. Meteorologists predict that around $1 \%$ of the solar radiation received will be converted into wind energy due to a strong temperature gradient that could lead to strong convection and thus wind. Since the energy content of solar radiation equals the world's total fossil fuel inventory in just 10 days, the potential for harnessing wind energy, which represents $1 \%$ of total solar radiation, is significant. Wind power generation is increasing dramatically globally as a technology choice for further capacity expansions in power systems. A survey was recently conducted to predict the monthly average wind speed in parts of Saudi Arabia using the kidnapper's induction mechanism to create a wind speed map for the entire country. Another study was conducted in Algeria to evaluate the wind speed reduction of $\mathrm{CO} 2$ emissions into the atmosphere through the development of a wind farm. Wind power has many advantages such as low cost, cleanliness and abundance. Unlike coal or oil, which produce harmful gases such as $\mathrm{CO}$, $\mathrm{CO} 2$, NOx and SOx, renewable energies are clean, free and abundant. There are no transport problems and no high technology is required to use wind energy. The technology of converting wind energy into mechanical and electrical energy is cheaper than other energy conversion systems. In areas with sufficient wind density, therefore, enormous economic benefits can be achieved by implementing wind energy conversion systems (WECS).

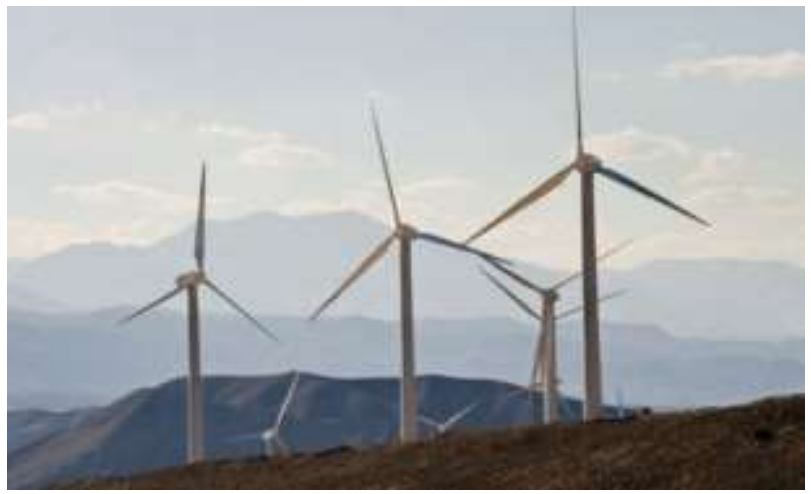

Fig. 1 wind farm 


\section{B. Hydropower Energy}

Hydropower supplies $20 \%$ of the world's electricity production. In fact, it rewards the best offer out of 55 countries. For many countries, hydroelectricity is the only source of domestic energy. The current role of hydropower in power generation is significantly broader than that of any other renewable energy technology, especially in less developed countries. It is limited to places where water is available and where geomorphology is appropriate. The flexibility of hydroelectric power and its reliable technology set it apart from other renewable energy sources. Since hydropower does not use or pollute water to generate electricity, there are fewer interruptions in the supply of clean water. At the same time, the proceeds from the sale of electricity can be invested to provide other comforts essential for human well-being. This may include drinking water supply systems, irrigation programs for food production, facilities to promote navigation, recreational facilities and ecotourism.

\section{Solar Energy}

Solar energy is another clean resource that has no direct negative impact on the environment. Abundant solar energy is often referred to as "alternative energy" to fossil fuels such as oil and coal. The depletion of fossil fuels has raised concerns around the world about the switch to solar energy. Although it is currently the most expensive type of renewable energy, accounting for only a small part of the world's energy needs (5\% of the total main energy supply), solar energy is a type of energy with a high future potential. In some parts of the world, it could be considered the best solution for decentralized energy supply today. To assess the global potential of solar energy, a study was conducted to estimate global solar radiation based on measurements from 52 cities in 11 different countries, which was complemented by an improved model to sufficiently estimate solar radiation with greater accuracy. According to the BP Statistical Energy Survey 2010, the installed solar power capacity worldwide was 22,928.9 MW, an improvement of $46.9 \%$ from 2008. Furthermore, various studies indicate that solar energy could become a probable future energy. This model predicted that solar power could provide a significant amount of energy throughout the year, especially in areas with high levels of solar radiation.

\section{Biomass Energy}

Biomass is gaining more and more attention as a clean alternative energy source to fossil fuels due to a dramatic increase in energy demand, rising fossil fuel prices and decreasing supply, as well as related environmental concerns, especially the greenhouse effect. Several bioenergy policies such as the Brazilian Biofuel Act, Indian Biofuel Policy, US Renewable Fuels Standard and European policies such as the Renewable Energy Directive, Biofuels Strategy and Biomass Action Plans, justify use biomass to reduce dependence on fossil fuels. and comply with greenhouse gas reduction strategies. These guidelines were developed as guidelines to ensure the sustainability of large-scale bioenergy crop production. The main negative impacts include direct and indirect changes in land use and biodiversity loss, availability of water supply, increased costs of agricultural products and risks to food security. These threats need to be weighed in terms of likely benefits such as improved greenhouse gas balance, business and income creation, agricultural development, conversion of dominant industries, and greater security of energy resources. .

Biofuels include a wide range of biomass-based fuels. The term includes solid biomass, liquid fuels and various biogas. First generation biofuels are obtained from sugars and vegetable oils present in arable land, which can be easily extracted using conventional technology. By comparison, second generation biofuels are produced from lignocellulose biomass or woody plants, agricultural residues or waste, making it difficult to obtain the necessary fuel. There are currently at least five different forms of biofuels:

(1) Bioethanol from starchy crops such as sugar cane, wheat, cassava, sorghum and corn;

(2) Biodiesel made from oil-rich seeds such as soy, oil palm and jatropha;

(3) Biogas produced by the biological decomposition of organic material such as animal or human waste is another biomass;

(4) cellulose-based bioethanol;

(5) Bio hydrogen produced from biomass or from the synthesis of methane by steam reforming. With the improvement of technology, cellulosic biomass such as trees and herbs is also used as a raw material for the production of ethanol. Ethanol in its pure form can be used as a vehicle fuel, but is commonly used as a gasoline additive to increase the octane number and improve vehicle emissions.

\section{E. Geothermal energy}

Geothermal energy is obtained naturally within the earth as a source of thermal energy. The origin of heat is related to the internal structure of the planet and the physical processes that take place there. Although heat is abundant in the earth's crust, let alone in the deepest places, it is unevenly distributed, rarely concentrated, and often at depths too great to be used mechanically. 
The geothermal gradient averages $30^{\circ} \mathrm{C} / \mathrm{km}$. There are areas within the earth that are accessible by drilling and where the slope is much greater than the average slope. Heat is obtained from geothermal reservoirs using wells and other means. Reservoirs that are warm enough and permeable by nature are called hydrothermal reservoirs, while reservoirs that are warm enough but are enhanced by hydraulic stimulation are called enhanced geothermal (ESG) systems. Once attracted to the surface, liquids at different temperatures can be used to generate electricity and for other purposes that require the use of thermal energy.

\section{CONCLUSION}

In recent decades, humans have recognized the need to develop clean renewable energy sources. Therefore, humanity has sought to reduce its energy consumption and develop clean energy sources to avoid its dependence on fossil fuels before these resources run out. In this article, wind energy is mentioned in renewable energy and solar energy. Therefore, we must find, use and develop new energy sources that do not have a negative impact on the environment and do not bother to integrate them.

\section{REFERENCES}

[1] JiY,Ai Q and Xie D 2010 Power System Technology vol 34 15-23

[2] Zhu X, Han X Q and Qin W P 2015 Renewable and Sustainable Energy Reviews vol 42 453-463

[3] Zhang H Y, Li S D 2011 Research on micro grid. Beijing, China:Tsinghua University 595-598

[4] Wu X,Yin X G and Song X 2013 Energy and Power Engineering 4 142-149

[5] Lu, Y.; Khan, Z.A.; Alvarez-Alvarado, M.S.; Zhang, Y.; Huang, Z.; Imran, M. A Critical Review of Sustainable Energy Policies for the Promotion of Renewable Energy Sources. Sustainability 2020, 12, 5078.

[6] Atika Qazi, FayazHussain "Towards Sustainable Energy: A Systematic Review of Renewable Energy Sources, Technologies, and Public Opinions" IEEE, vol. 7, pp. 63837 - 6385123 May 2019.

[7] P. Asantewaaowusu, Samuel Asumadusarkode "A review of renewable energy sources, sustainability issues and climate change mitigation" Cogent Engineering, Volume 3, Issue 1, 2016.

[8] Ed. KazimierasZavadskas, FaustoCavallaro and ZainabKhalifah "Sustainable and Renewable Energy: An Overview of the Application of Multiple Criteria Decision Making Techniques and Approaches" vol. 7, 13947-13984; doi:10.3390/su71013947, Sustainability 2015.

[9] Abbas Azarpour, Suardi Suhaim "A Review on the Drawbacks of Renewable Energy as a Promising
Energy Source of the Future" Arab J Sci Eng 38:317328, 2013. 